\title{
Experimental investigations of ice slurry flow based on monoethylene glycol at high ice fractions
}

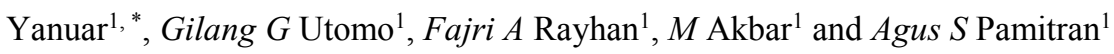 \\ ${ }^{1}$ Department of Mechanical Engineering, Universitas Indonesia, Depok 16424, Indonesia
}

\begin{abstract}
Ice slurry has so many advantages as phase-change slurries due to the high latent heat of its particles. Ice slurry is one of a competitive alternative to conventional secondary refrigeration systems that have been successfully employed in many applications. In this research, ice slurry flow with monoethylene glycol (MEG) at high ice fractions was investigated. The experiment was carried out by measuring shear stress and flow rate as variable to calculate power law index. The experiment was performed in $14 \mathrm{~mm}, 21$ $\mathrm{mm}$, and $24 \mathrm{~mm}$ circular tubes, respectively. The Initial concentration of $5 \mathrm{wt} \%$, $7 \mathrm{wt} \%$, and $10 \mathrm{wt} \%$ of MEG was investigated. Ice fraction was maintained above $30 \%$ in a storage tank. Experimental results of the Darcy friction factor were compared to Poiseuille and Blasius model. The ice slurry flows exhibited a shear-thickening flow $(n>1)$ for all initial concentration in the range $1.07-1.58$. The Greater initial concentration of MEG tends to give smaller friction compared with another ice slurry flow with smaller initial concentration.
\end{abstract}

\section{Introduction}

Ice slurry is a two-phase fluid (solid-liquid) made from a mixture of aqueous solutions between water as a solvent and an additive as a solute. There are numbers of additives compound which are widely used in the generation of ice slurry, including sodium chloride, glycol, alcohol, and others. According to Egolf and Kauffeld [1], the definition of ice slurry can be described as follows:

- Ice slurry consists of a number of ice particles in aqueous solution.

- Fine-crystalline ice slurry is ice slurry with ice particles with average characteristics diameter, which is equal to or smaller than $1 \mathrm{~mm}$.

Ice slurry is a promising thermal energy storage technology, because of their advantages regarding the environment, which is the most important challenge ahead of us, along with the safety of course. Ice slurry as a secondary refrigerant has high cooling capacity given by the latent heat of phase change. However, there is still need a lot of research, particularly on how to generate ice slurry in an efficient, reliable and economical way for use in a broader range of applications [2].

The ice slurry has been utilized widely in industrial applications. Bellas and Tassou [3] classified the application of ice slurry into three main sections: comfort cooling, food engineering applications and specialist and future applications that may result from on-going research and development work.

Over the 20 years, scientists and scholars have not agreed on the flow characteristics of ice slurry. Sasaki, et al. [4] classified ice slurry fluids as a non-Newtonian type of dilatant or shear-thickening fluids. Christensen and Kauffeld [5] proposed a modified Bingham model to describe ice slurry flow, which was originally completed from the model proposed by Papanastasiou [6]. The classification of this type of fluid is essential to support the application and ease of transportation of ice slurry fluids for their use worldwide, especially in Indonesia.

This study was aimed to experimentally investigate the non-Newtonian behavior of ice slurry flow in circular pipes. The type of ice slurry flows whether pseudoplastic or dilatant form with the variations of initial concentration of water-MEG solutions is conducted.

\section{Theoretical Analysis}

In this experiment, ice slurry was considered a kind of multi-phase fluid, with ice particles as the solid phase and its cold brine as the liquid phase. Ice slurry was observed to figure out its non-Newtonian fluid characteristic.

There are some the rheological formulas to determine the non-Newtonian characteristic. The formulas for calculating shear stress and shear rate are presented below.

$$
\begin{gathered}
\tau=D \Delta P / 4 L \\
\dot{\gamma}=8 U / D
\end{gathered}
$$

Where $\tau=$ shear stress $(p a), D=$ diameter of pipe $(m)$, $\Delta P=$ pressure drop $(p a), L=$ length of pipe $(m), \dot{\gamma}=$ shear rate $(1 / \mathrm{s})$ and $U=$ velocity of flow $(\mathrm{m} / \mathrm{s})$

\footnotetext{
${ }^{*}$ Corresponding author: yanuar@eng.ui.ac.id
} 
Ice slurry is considered a non-Newtonian fluid, it can be classified either as pseudo plastic or dilatant fluid. The equation for calculating the non-Newtonian fluid is presented below.

$$
\begin{aligned}
& \tau=K(\dot{\gamma})^{n} \\
& n=\frac{d \ln \left(\frac{D \Delta P}{4 L}\right)}{d \ln \left(\frac{8 U}{D}\right)}
\end{aligned}
$$

Where $K=$ index consistency $[p a \cdot s]$ and $n=$ power law index $[-]$.

If the power law index of fluid is less than one $(n<1)$, the fluid flow is pseudoplastic or shear thinning. Otherwise, if the power law index is exceeding $1(n>1)$, the fluid flow appears to be dilatant or shear thickening.

The friction factor can be calculated using the Darcy-Weisbach equation:

$$
f_{D}=\left(\frac{D}{L}\right)\left(\frac{2}{\rho U^{2}}\right) \Delta P
$$

Where $f_{D}=$ Friction factor of Darcy Weisbach (-) and $\rho=$ density of $\left(\mathrm{kg} / \mathrm{m}^{3}\right)$

The flow characteristics of ice slurry under laminar and turbulent flow were investigated, and the theoretical values of the coefficient friction can be described using the following equations:

For laminar

$$
f=64 / R e^{\prime}
$$

For turbulent

$$
f=0.3164 \cdot R e^{\prime-1 / 4}
$$

Where $f=$ Friction factor $(-)$ and $R e^{\prime}=$ generalized Reynolds number $(-)$.

From the Eq. 5, different size pipes will impact on the pressure drop, significantly. The larger the pipes, the smaller pressure differences.

The equation for the generalized Reynold number of ice slurry flow that proposed by Mellari [7] can be described using the following equations:

$$
R e^{\prime}=\frac{\rho \cdot D^{n} \cdot U^{2-n}}{K} \frac{1}{8^{(n-1)} \cdot\left(\frac{1+3 n}{4 n}\right)^{n}}
$$

\section{Experimental Setup}

The experiment started with the preparation of the pipe test. There are three different pipe diameter which was used for the experiment, the 14,21 , and $24 \mathrm{~mm}$ circular pipe, respectively. Trundean TMD-25 magnetic pump used for discharging the ice slurry from the storage tank. The variation of flow velocity was adjusted by the inverter device which was linked to the pump. The schematic pipe flow is presented in Fig 1.

In this experiment, the freezing point depressant which was used for lowering the temperature was monoethylene glycol (MEG). There are three variations of initial concentration, $5 \mathrm{wt} \%, 7 \mathrm{wt} \%$, and $10 \mathrm{wt} \%$. Ice slurry was produced approximately 2 hours by using the scrapper-type ice slurry generator. Ice fraction was maintained above $30 \%$ in the storage tank that calculated by the following equation:

$$
X_{i}=\frac{\left[C_{S}(T)-C_{o}\right]}{C_{S}(T)}
$$

Where $X_{i}=$ ice mass fraction $(-), C_{o}=$ initial concentration of mixture $\left(\mathrm{m}^{3} / \mathrm{m}^{3}\right)$, and $C_{s}(T)=$ final concentration of ice slurry as function of temperature $\left(\mathrm{m}^{3} / \mathrm{m}^{3}\right)$.

If thermal leakage happened, ice slurry would have gained heat and melted the ice fraction. This certain thing will make the measurement of solid ice particle inaccurate because solid ice will keep melting and the number of ice fraction will reduce continuously during measurement. Method for determining the solid ice fraction of ice slurry will be interesting to be researched.

For the rheological behavior test, ice slurry was flowing through each circular pipe with different volume flow rate. The measuring tank was installed to measure the flow rate of ice slurry.

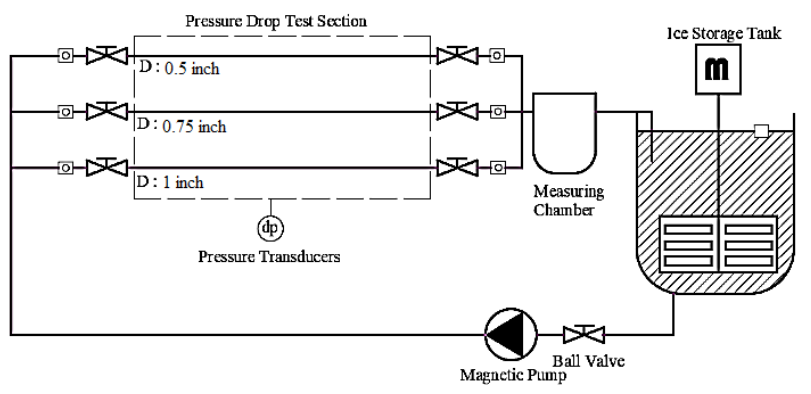

Fig. 1. Schematic diagram of ice slurry test section

\section{Result and Discussion}

After producing ice slurry for 2 hours, the temperature for $5 \mathrm{wt} \%, 7 \mathrm{wt} \%$, and $10 \mathrm{wt} \%$ were $-1.60^{\circ} \mathrm{C},-2.20^{\circ} \mathrm{C}$, and $3.80^{\circ} \mathrm{C}$, respectively. It showed that the more portion of the initial mixture of additive resulted in the lower temperature of ice slurry. This is a good condition producing ice slurry with low temperature for industrial application. However, the structure of ice slurry would be different for certain initial concentration. Ice slurry with 5 $w t \%$. initial concentration had coarser solid ice particles than ice slurry with $10 \mathrm{wt} \%$. This is because the more containment of antifreeze depressant tends to lower down the freezing point temperature and ice slurry with less initial concentration tended to form solid ice particles quicker compared to those with higher initial concentration.

The result for ice slurry flow experiment will be illustrated in 3 graphs: shear stress versus shear rate, apparent viscosity versus shear rate, and friction coefficient vs generalized Reynold number diagrams.

The shear stress vs shear rate graphs that resulted for three different test pipes show in figure 2, 3 and 4. 


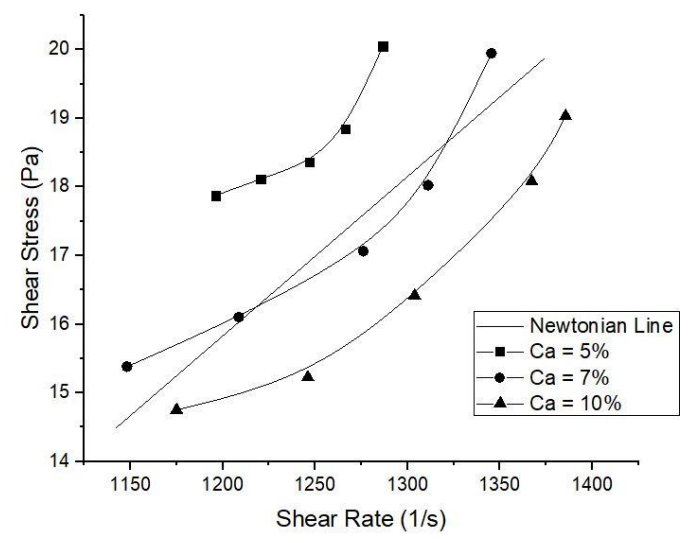

Fig. 2. Shear stress of ice slurry flow in $14 \mathrm{~mm}$ pipe

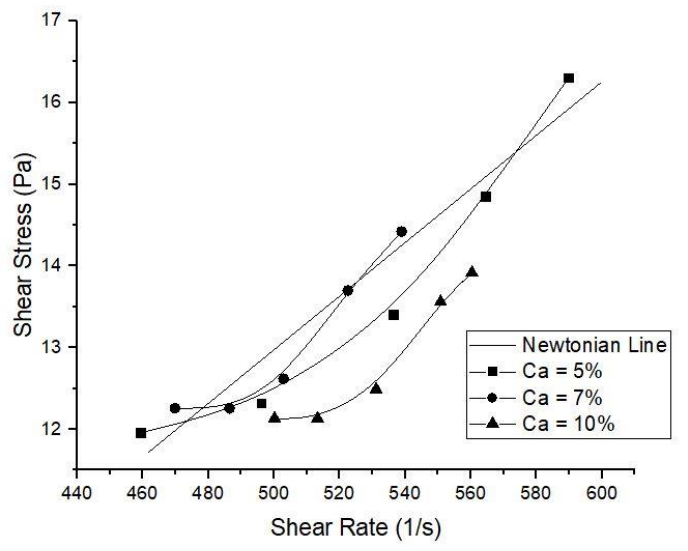

Fig. 3. Shear stress of ice slurry flow in $21 \mathrm{~mm}$ pipe

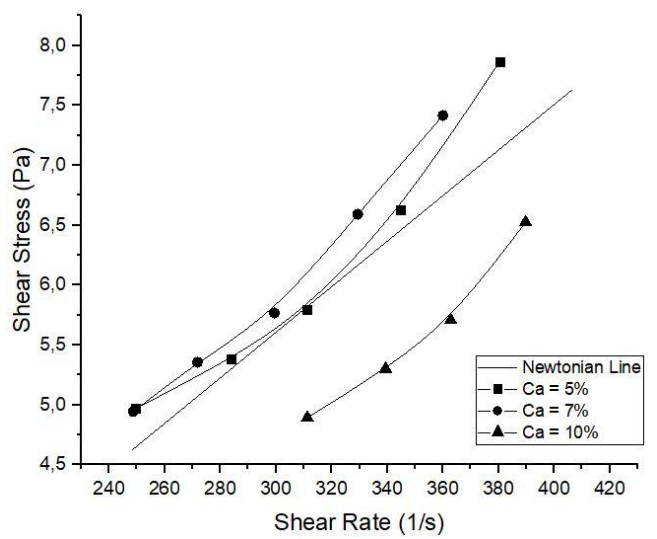

Fig. 4. Shear stress of ice slurry flow in $24 \mathrm{~mm}$ pipe

From the diagrams as illustrated above, it can be seen that the fluid flow of ice slurry behaves like dilatant fluid or shear thickening. Power law index from figures was analyzed by the logarithmic scale. Summarize of the power-law index of ice slurry flow are presented in Table 1.
Table 1. Power law index of ice slurry flow

\begin{tabular}{|c|c|c|c|}
\hline \multirow{2}{*}{$\begin{array}{c}\text { Pipe Size } \\
(\mathrm{mm})\end{array}$} & \multicolumn{3}{|c|}{ Initial Concentration of MEG } \\
\cline { 2 - 4 } & $5 \%$ & $7 \%$ & $10 \%$ \\
\hline 14 & 1,43 & 1,50 & 1,54 \\
\hline 21 & 1,24 & 1,26 & 1,29 \\
\hline 24 & 1,07 & 1,09 & 1,11 \\
\hline
\end{tabular}

From the Table 1, the range value of the power-law index from $14 \mathrm{~mm}$ diameter pipe is different 21 and 24 $\mathrm{mm}$. In the smallest pipe, the range of the power-law index is varied from 1.43 to 1.54 . In contrary with the large pipe $(24 \mathrm{~mm})$, the range of the power-law index is the varied from 1.07 to 1.11 . In this case, for the nonNewtonian dilatant form of fluid can be little more beneficiary by using larger pipe. With the power law index exceeding 1 , the numbers of shear stress and also pressure drop will increase as shear rate or flow velocity raising. The further investigation needs to be done regarding pipe size for the dilatant form of fluid to obtain the optimum pipe size for flowing the dilatant or other non-Newtonian flow. This trend of non-Newtonian flow is similar to that obtained Mellari [7] and Grozdek [8].

Figures 5, 6 and 7 shown apparent viscosity vs shear rate of ice slurry flow for different test pipe, $14 \mathrm{~mm}, 21$ $\mathrm{mm}$, and $24 \mathrm{~mm}$, respectively. It was found that the values of apparent viscosity were raising as the rate of shear increasing. Thus, the flow of non-Newtonian fluid of ice slurry shows as the dilatant pattern or shear thickening flow in high ice fraction. From the graph in Fig. 5, 6, and 7 can also be seen that the use of larger pipe $(24 \mathrm{~mm})$ for flowing ice slurry, resulted in higher apparent viscosity compared to the use of smaller pipe $(14 \mathrm{~mm})$. This occurred because the power law index occurred in each pipe. The higher value of the power law index generated lower apparent viscosity for different initial concentration, as shown in Fig. 5. Otherwise, the smaller value of the power law index resulted in higher apparent viscosity, as shown in Fig. 7.

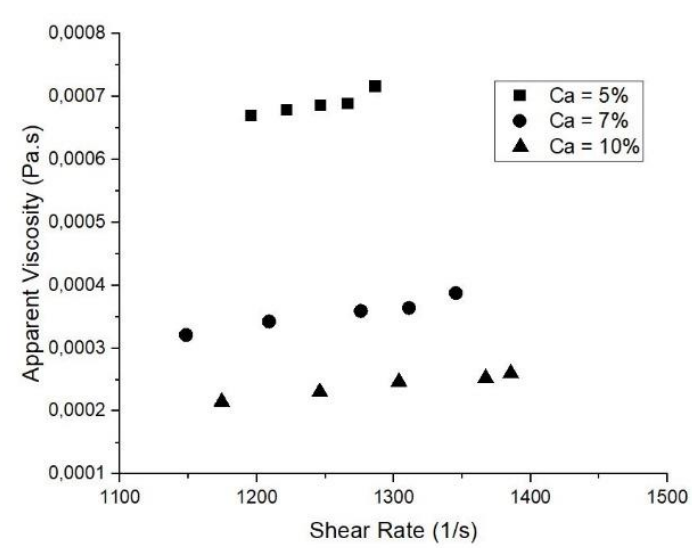

Fig. 5. The apparent viscosity of ice slurry flow in $14 \mathrm{~mm}$ pipe 


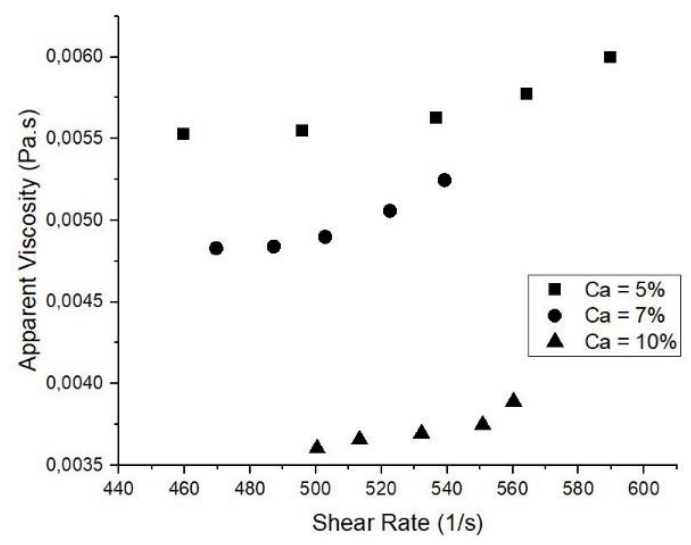

Fig. 6. The apparent viscosity of ice slurry flow in $21 \mathrm{~mm}$ pipe

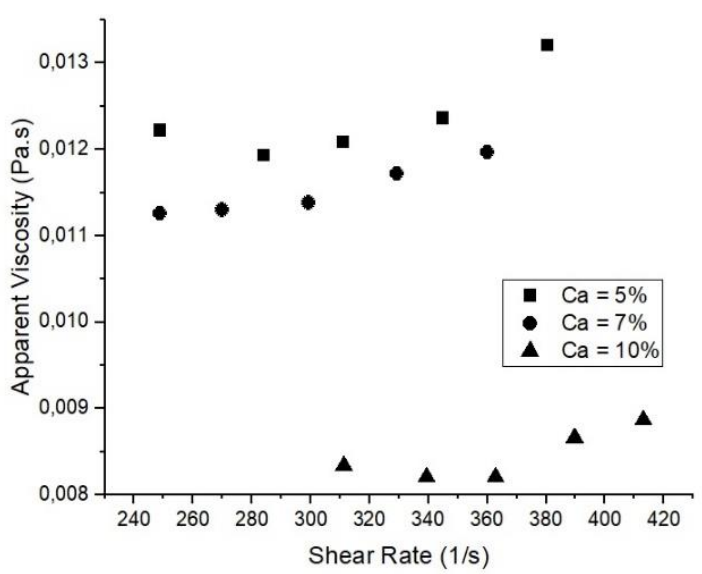

Fig. 7. The apparent viscosity of ice slurry flow in $24 \mathrm{~mm}$ pipe

Figures 8,9 and 10 shown friction coefficient vs generalized Reynold number for different test pipes, 14 $\mathrm{mm}, 21 \mathrm{~mm}$, and $24 \mathrm{~mm}$, respectively. The calculation of Reynold number for non-Newtonian flow is measured by generalized Reynold number to determine the laminar or turbulent regime of flow. From the figures, the friction factor of ice slurry was not giving a good agreement for Hagen Poiseuille equation line, because ice slurry has a solid particle effect that increases the friction factor of flow. Therefore, ice slurry flow tends to affect the power law index value, significantly.

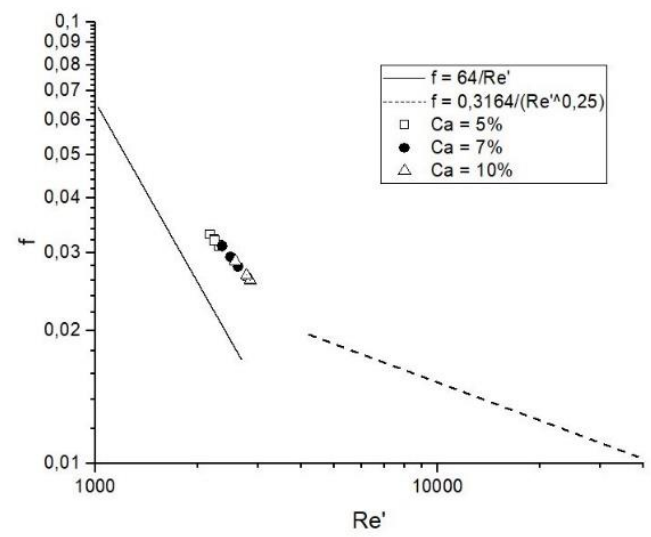

Fig. 8. The friction coefficient of ice slurry flow in $14 \mathrm{~mm}$ pipe

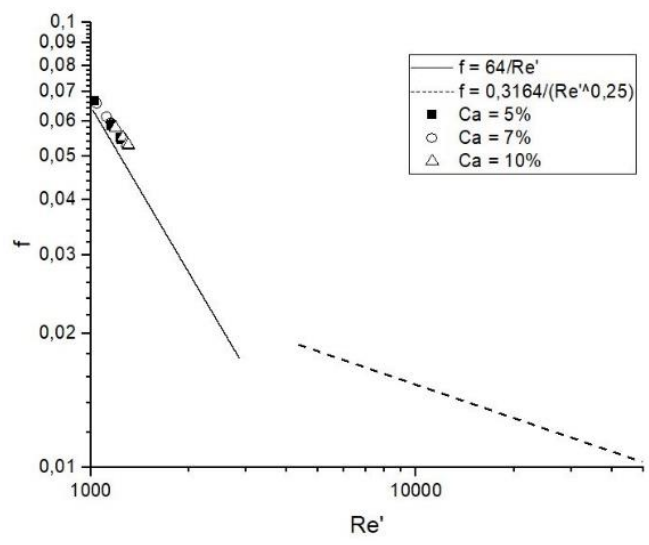

Fig. 9. The friction coefficient of ice slurry flow in $21 \mathrm{~mm}$ pipe

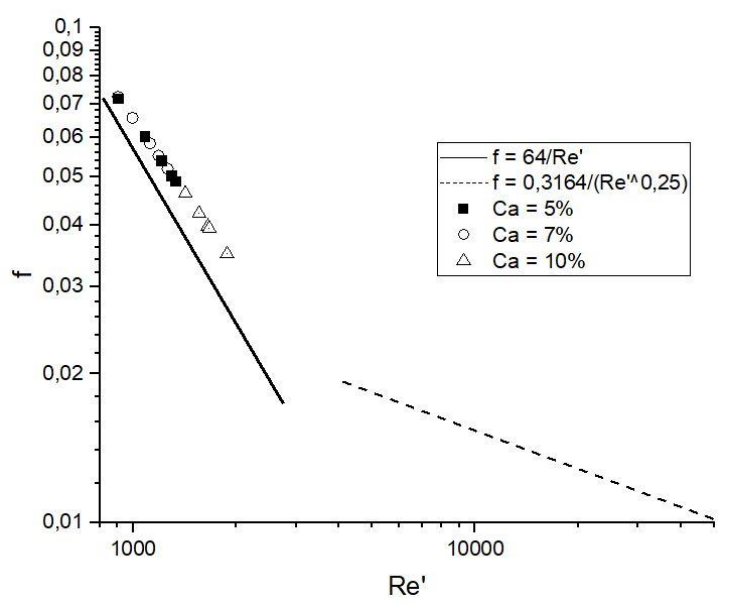

Fig. 10. The friction coefficient of ice slurry flow in $24 \mathrm{~mm}$ pipe

Additionally, there is a correlation between the number of friction for ice slurry with initial solutions concentration added. For ice slurry with initial concentration $10 \mathrm{wt} \%$ shows smaller friction than $5 \mathrm{wt} \%$ and $7 \mathrm{wt} \%$. This shows that MEG as an additive can also serve as a friction reducing agent. The larger amount of additive added in a fluid, the more efficient of the fluid flowing in medium because the friction flow can be reduced, also the shear stress and pressure drop of the fluid flow can be minimized.

\section{Conclusions}

This research was conducted to understand the flow of ice slurry in three different sizes of pipes. For every result obtained, the flow of ice slurry tended to form dilatant or shear-thickening flow. Each pipe resulted in the range value of the power law index differently due to the different shear stress occurred in each pipe. The smaller the test pipe used, the higher index of power-law occurred in the flow. In this experiment, it was found that if ice slurry flow occurred in the pipe get faster, the flow itself become more viscous as seen from the apparent viscosity graphs. The correlations of friction coefficient versus generalized Reynold number showed that flow of ice 
slurry with initial concentration $10 \mathrm{wt} \%$ tends to give smaller friction compared with another ice slurry with different initial concentration.

Authors are thankful to the laboratory of refrigeration, Department of Mechanical Engineering, Faculty of Engineering, Universitas Indonesia for making the facility available and also grant PITTA No. 2561/UN2.R3.1/HKP 05.00/2018

\section{References}

1. P.W. Egolf M. Kauffeld From physical properties of ice slurries to industrial ice slurry applications International Journal of Refrigeration 28 4-12 (2005)

2. M. Kauffeld, M. Kawaji P.W. Egolf Handbook on ice slurries International Institute of Refrigeration, Paris 359 (2005)

3. I. Bellas S.A. Tassou Present and future applications of ice slurries International Journal of Refrigeration 28 115-21 (2005)

4. M. Sasaki, T. Kawashima H. Takahashi 1993 Dynamics of snow-water flow in pipelines, slurry handing and pipeline transport. In: Hydrotransport, pp 533-613

5. K.G. Christensen M. Kauffeld 1997 Heat transfer measurements with ice slurry: Institut international du froid)

6. T.C. Papanastasiou Flows of materials with yield Journal of Rheology 31 385-404 (1987)

7. S. Mellari Experimental investigations of ice slurry flows in horizontal pipe based on monopropylene glycol International Journal of Refrigeration 65 27-41 (2016)

8. M. Grozdek, R. Khodabandeh P. Lundqvist Experimental investigation of ice slurry flow pressure drop in horizontal tubes Experimental Thermal and Fluid Science 33 357-70 (2009) 